\title{
MATERIAIS DIDÁTICOS E ENSINO NA ESCOLA BÁSICA: IMPACTOS NO CURRÍCULO E NA PRODUÇÃO EDITORIAL BRASILIERA ${ }^{1}$
}

\author{
Célia Cristina de Figueiredo Cassiano \\ f.cassiano@uol.com.br
}

\section{INTRODUÇÃO}

Apresentamos, de modo geral, como as políticas educacionais e o mercado editorial brasileiro impactaram o currículo desenvolvido nas escolas públicas do país de educação básica, em um campo de disputa que se acirra nos anos 2010, com a entrada da editora inglesa Pearson no país, pela compra de quatro "Sistemas Apostilados de Ensino". Nesse processo, educação pública e capital privado tem seus limites reconfigurados com nova ordenação que apresenta as marcas de um mundo globalizado, tecnológico e capitalista.

Inicialmente, vale destacar que o segmento dos didáticos é o mais rentável do mercado editorial, ainda que tais livros não tenham prestígio proporcional, pois eles têm sua vida útil atrelada ao ano escolar, não sendo livros que têm status de literatura. Em 2010, a Câmara Brasileira do Livro (CBL) e o Sindicato Nacional dos Editores de Livros (SNEL) divulgaram o estudo Produção e vendas do setor editorial brasileiro (2009), encomendado para a Fundação Instituto de Pesquisas Econômicas (FIPE),

${ }^{1}$ Este artigo se desdobra da tese de doutoramento de minha autoria, Mercado do livro didático no Brasil. 
com representatividade de $78 \%$ do mercado editorial no Brasil. O estudo indicava que $51 \%$ dos livros vendidos no Brasil, em 2009, considerando-se o faturamento, foram didáticos; $15 \%$ científicos, técnicos e profissionais; $10 \%$ religiosos e $24 \%$ obras gerais.

Essa liderança dos didáticos, no segmento editorial, se dá por conta do Programa Nacional do Livro Didático - PNLD, política pública federal de compra e distribuição de livros didáticos para todos os alunos matriculados nas escolas públicas do ensino básico do país, criado em 1985 .

Em 1996, com a Lei de Diretrizes e Bases da Educação Nacional - LDB 9394/96, surgiu nova orientação curricular para as escolas da educação básica no Brasil, que foi implementada, em grande parte, pela distribuição gratuita do livro didático para os alunos dos ensinos fundamental de todas as escolas públicas do país, por meio do PNLD.

De modo geral, essa é a conjuntura que consolidou o governo brasileiro como o maior comprador de livros do país (de acordo com o ano analisado, quiçá seja o maior comprador do mundo, quando se pensa em termos de distribuição) e o ramo dos didáticos como o mais rentável no mercado nacional dos livros.

Esse panorama, então, atraiu a atenção das editoras espanholas, que já estavam consolidadas na maior parte dos demais países da América Latina, mas que ainda não haviam entrado no Brasil, cujo mercado editorial representa, aproximadamente, $40 \%$ da América Latina.

No caso da entrada da editora espanhola Santillana, no Brasil (em 2001), entre várias outras possibilidades de análise, vale destacar a edição das "obras coletivas", prática editorial até então inédita no país. Além disso, a editora também passou a comercializar os "sistemas apostilados de ensino", como outras grandes editoras do país. Neste caso, chama a atenção que a Santillana também passou a comercializar este tipo de produto em outros países da América Latina, visto ter a liderança no ramo em boa parte do continente. Esses materiais didáticos que entram em significativo número de escolas sul-americanas por meio desta editora implicam alterações significativas para o currículo desenvolvido nessas instituições educacionais e também reconfiguram o mercado editorial, dadas as especificidades desses materiais, que são mais rentáveis para as editoras, como veremos posteriormente.

Vale salientar, porém, que a comercialização dos "sistemas apostilados de ensino" para as escolas públicas é fenômeno recente e polêmico, uma vez que, no Brasil, tais materiais são vendidos diretamente às prefeituras, que adquirem esse material didático (sem autoria), formação de professores e todo o currículo organizado sem nenhum tipo de avaliação, sendo que também não há licitação pública para essa compra. 
Aliás, essa foi a "porta de entrada" dogrupo inglês Pearson na educação brasileira, por meio da aquisição dos Sistemas de Ensino do Grupo SEB: COC, Pueri Domus, Dom Bosco e Name; que já têm expressividade no mercado escolar brasileiro. O grupo Pearson é dono das mais influentes editoras, jornais e revistas do mundo, como a Penguin Books, o Financial Times e a The Economist, por exemplo. Nesse processo, o grupo ingressa no mercado dos sistemas de ensino ficando atrás, apenas, do grupo Positivo, até então líder desse segmento no país.

Na década de 2010, pode-se constatar que cada vez mais municípios compram Sistemas de Ensino, com verbas próprias (em detrimento do recebimento gratuito dos livros didáticos enviados pelo governo federal) e, ao fazerem-no, todo o currículo da educação pública local passa a ser de total competência de instituições privadas, que visam o lucro. Nesse sentido, o poder público "abre mão" de um elemento fundamental de seu sistema educativo, o currículo, para deixa-lo nas mãos de empresas privadas, nacionais e internacionais.

Assim, apresentamos como esses processos ocorreram, bem como algumas tendências implicadas para o currículo desenvolvido nas escolas, que remetem a uma reflexão sobre os limites entre público e privado na educação pública brasileira.

\section{O livro didático na educação e o PNLD}

O livro didático tem sua essência atrelada à cultura escolar, assim, além dos conteúdos pedagógicos contidos nesses livros e suas implicações curriculares (considerando sua produção - o autor, editor etc.; e seu uso docentes, alunos etc.), há de se levar em conta que também incidem neste tipo de livro intervenções estatais (à luz das políticas públicas) e regulações de mercado (uma vez que no Brasil os livros didáticos são editados por empresas privadas que visam o lucro). Historicamente, então, controle estatal e influências comerciais nos livros didáticos variam conforme o período histórico analisado.

Praticamente $50 \%$ de todos os livros que circulam no país são didáticos, porque por meio do Programa Nacional do Livro Didático $P N L D$, o governo compra, de modo regular e planejado, livros didáticos de todas as disciplinas para distribuir a todos os alunos que estão na educação básica da rede pública de ensino, como já se disse.

O expressivo volume de livros didáticos que circula no Brasil, no início do século XXI resultante, sobretudo, do PNLD - situa o governo brasileiro, comprovadamente, desde 1996, como o maior comprador de livros do país. 
Isso ocorre porque os alunos dos dois níveis de ensino atendidos pelo Estado, ou seja, o ensino fundamental e médio, representam, aproximadamente, $90 \%$ de toda a educação básica do Brasil, que tem números expressivos, como pode ser visto na Tabela 1.

Tabela 1: Número de Matrículas na Educação Básica do Brasil - 2012

\begin{tabular}{|l|r|r|r|}
\hline Nível de ensino & Total de matrículas & \multicolumn{1}{c|}{ Rede Pública } & \multicolumn{1}{c|}{ Rede Privada } \\
\hline Educação Infantil & 7.295 .512 & 5.190 .128 & 2.105 .384 \\
\hline Ensino Fundamental & 29.702 .498 & 25.431 .566 & 4.270 .932 \\
\hline Ensino Médio & 8.376 .852 & 7.310 .689 & 1.066 .163 \\
\hline Educação Profissional & 1.063 .655 & 407.689 & 607.336 \\
\hline Educação de Jovens e Adultos & 3.906 .877 & 3.775 .904 & 130.973 \\
\hline Educação Especial & 199.656 & 58.225 & 141.431 \\
\hline Total & 50.545 .050 & 42.222 .831 & 8.322 .219 \\
\hline
\end{tabular}

INEP, 2013. Censo Escolar da Educação Básica 2012/ Resumo Técnico. Dados organizados pela pesquisadora.

Vale retomar que, salvo raras exceções, praticamente todos os alunos matriculados na educação básica, tanto pública quanto privada, usam o livro didático, e isto justifica o impressionante volume desse produto que circula anualmente no país.

Historicamente, considero que há dois marcos que referenciam o PNLD. Em 1985 esse Programa foi criado e fazia parte de outras políticas sociais instituídas pelo governo, que queria dar sua marca na redemocratização do país. Porém, neste período, a aquisição e a distribuição de livros didáticos, apesar de significativas, não eram universais (no sentido de atender a todos os alunos da educação básica da rede pública) e sequer tinham regularidade.

O PNLD passa a ter universalidade na distribuição dos livros e regularidade nos recursos aplicados a partir do que considerei como o seu segundo marco, que se dá em 1996, à luz reformas na educação implementadas pelo governo Fernando Henrique Cardoso, em que se implementa, gradativamente, a compra e a distribuição universal de livros didáticos (de todas as disciplinas escolares e para todos os níveis de ensino) para os estudantes da educação básica da rede pública brasileira.

A resolução no 6o, de 20 nov. 2009 (alterada pela resolução ํㅜ 10, de 10 mar. 2011), e o Decreto no 7084/2010 dispõem sobre os Programas de Materiais Didáticos e contemplam todas essas alterações em relação ao Ensino Fundamental de nove anos, e também em relação à ampliação do PNLD em vários programas. 
Ou seja, no início dos anos 2010 há, aproximadamente, 38 milhões de alunos matriculados na educação básica brasileira (INEP, 2013) sendo que 33 milhões estão na rede pública, contrapondo-se aos 5 milhões de alunos matriculados na rede particular de ensino, como pode ser observada a Tabela 1.

Segundo o FNDE (Fundo Nacional de Desenvolvimento da Educação), para o PNLD 2012, o governo investiu R\$1.326,5 bilhões na compra, avaliação e distribuição de 160 milhões de livros didáticos para serem usados pelos alunos matriculados nos diferentes níveis de Ensino da Educação Básica Pública.

Certamente, tais dados possibilitam compreender porque nenhum segmento no setor do livro tem um universo tão grande de leitores certeiros e regulares, como é o caso dos didáticos, constituindo-se, portanto, em privilegiado campo de disputa das maiores editoras do país. Mesmo que usado de diferentes formas por docentes e alunos, certamente pode-se dizer que tais livros dão seu marco nos currículos desenvolvidos nas mais de 120.000 escolas públicas distribuídas por todos os municípios brasileiros, sendo este ainda um dos principais recursos didáticos usados nas escolas de educação básica. Nesta perspectiva, reafirmamos que o livro didático ainda se constitui, hoje (2013), como importante recurso didático no Brasil. Devido às dimensões do país, que conta com mais de 5.500 municípios, bem como considerando sua diversidade socioeconômica e cultural, há lugares em que o didático é o único livro que algumas pessoas têm acesso na vida porque, como já vimos, há algumas décadas o governo garante que todos os estudantes da rede pública tenham acesso a tais livros.

Assim, provavelmente, um aluno da rede pública de uma capital terá mais condições de ter acesso a outros recursos - advindos das novas tecnologias, por exemplo - do que um aluno que estuda em municípios mais distantes em que o acesso ao livro entregue pelo correio ainda faz a diferença. Vale destacar que o correio brasileiro já ganhou importantes prêmios mundiais por distribuir, com competência, o impressionante número de livros comprados por meio do PNLD anualmente, para as escolas públicas distribuídas do Oiapoque ao Chuí no Brasil. Ou seja, de uma forma ou de outra (por embarcações, por exemplo) é certeza de que os livros didáticos chegam a todas as escolas públicas do país.

\section{Avaliação dos livros didáticos no PNLD}

Ogovernobrasileirosócompralivrosdidáticosqueatendamaumasérie de critérios de qualidade (pedagógica e técnica) instituídos anualmente 
em editais. Na instância pedagógica, quem avalia essa "qualidade" são comissões de técnicos vinculadas a diferentes Universidades no país (que variam conforme a disciplina analisada e modalidade de ensino objetos da compra estatal do livro) que aprovam ou reprovam os livros a serem comprados pelo governo.

Assim, em 1993, no ano da publicação do Plano Decenal de Educação para Todos, o Estado - que até então mantivera o papel de comprador e distribuidor de livros didáticos por meio do PNLD, pela Portaria 1.130, de 6 de agosto de 1993 - constitui uma comissão para analisar a qualidade dos conteúdos programáticos e dos aspectos pedagógico-metodológicos dos livros que vinham sendo comprados pelo MEC para as séries iniciais do Ensino Fundamental, assim como para poder estabelecer critérios para novas compras governamentais. Tal comissão analisou os dez livros mais solicitados de cada disciplina pelos professores das escolas públicas.

Em 1994, por meio da imprensa, os resultados desse estudo foram divulgados pelo governo, sendo demonstrado que o MEC vinha comprando e distribuindo, para a rede pública de ensino, livros didáticos preconceituosos, desatualizados e com erros conceituais.

Em 1996, o MEC implantou oficialmente a avaliação pedagógica dos livros didáticos comprados por meio do PNLD. O Ministério da Educação formou comissões, divididas por áreas de conhecimento (Alfabetização e Língua Portuguesa; Matemática; Ciências e Estudos Sociais; posteriormente, Geografia e História), para estabelecer quais seriam, efetivamente, os critérios de análise e classificação dessa avaliação. Desde essa época, o resultado desse processo passou a ser condensado e divulgado por meio de exemplares denominados Guias de Livros Didáticos, que são distribuídos nacionalmente para as escolas, com o objetivo de orientar os professores na escolha do livro didático. Desse modo, a avaliação dos livros e a distribuição desses Guias de Livros Didáticos fazem parte da operacionalização do PNLD.

É esse, portanto, o início do processo oficial de avaliação dos livros didáticos adquiridos pelo governo para a rede pública de ensino, mas que também repercutiu na rede particular, uma vez que foi objeto da mídia e configurou discussões com formadores de opinião.

Quando a avaliação dos livros didáticos foi implementada oficialmente, em 1996, ficava sob a responsabilidade da Secretaria de Educação Fundamental (SEF), e contava com equipes de avaliações por áreas de conhecimento, que tinham a coordenação de especialistas das diferentes áreas.

Os pareceres consolidados seguiam para o Centro de Estudos e Pesquisas em Educação, Cultura e Ação Comunitária (Cenpec), que 
os editava em forma de resenha, exceto os livros de Alfabetização e Língua Portuguesa, que já eram avaliados e resenhados pelo Centro de Alfabetização, Leitura e Escrita (Ceale).

Para oPNLD 2002, oficialmentea avaliaçãodos livros didáticos passoua ser feita diretamente pelas universidades de vinculação dos coordenadores de áreas, salvo raras exceções, cabendo à SEB a coordenação-geral desse processo. Porém, os coordenadores de área sempre foram os mesmos. Ao que tudo indica, não houve alteração com a nova medida anunciada pelo governo.

De qualquer forma, Alfabetização e Língua Portuguesa ficaram oficialmente sob a responsabilidade da Universidade Federal de Minas Gerais (UFMG). Os professores Antonio Augusto Gomes Batista, Magda Soares e Maria da Graça Val, além de docentes dessa universidade, também são pesquisadores do Ceale, instituição fortemente envolvida no processo da avaliação dos livros didáticos desde sua implementação, como já se disse.

No caso da área de Língua Portuguesa, apesar de a área ser diretamente vinculada à Universidade Federal de Minas Gerais (UFMG), os professores Egon de Oliveira Rangel e Roxane Rojo - esta também participante da equipe do Ceale que, em 2006, passou a ser docente da Universidade Estadual de Campinas (Unicamp), responsáveis pela coordenação da área, pertenciam ao quadro de docentes da Pontifícia Universidade Católica de São Paulo (PUC-/SP).

Esses especialistas (e outros das demais áreas), na qualidade de coordenadores da avaliação dos livros didáticos, produziram bibliografia que diz respeito diretamente ao PNLD e acerca da avaliação que foi instituída. Também divulgaram determinadas concepções teóricometodológicas relativas ao ensino-aprendizado das áreas, na Educação Básica, em que são responsáveis pela avaliação - o que é natural, dado o posto que ocupem. Tais concepções, via de regra, respaldam os Parâmetros Curriculares Nacionais destinados ao Ensino Fundamental. Nesse sentido, Batista (1997, 2001, 2002, 2003), Rangel (2001), Rojo (2005), Rojo e Batista (2003), Bezerra e Luca (2006), Sposito (2006) e Bizzo (2000) são alguns exemplos dessa produção. Acrescentam-se a tais produções várias outras publicações editadas diretamente pelo MEC, que não cabe enumerar aqui.

Há, então, uma disseminação da informação sobre o PNLD e, particularmente, dos processos que envolveram a avaliação dos livros didáticos, advinda, prioritariamente, desse grupo de formadores de opinião que legitimam esse processo.

Lembremo-nos de que, norteando a avaliação dos livros didáticos, além dos critérios de qualidade, temos também os Parâmetros Curriculares Nacionais (PCNs). De acordo com o então ministro Paulo Renato de Souza: 
Ao final, prevaleceu a orientação de elaborar um parâmetro curricular nacional ou um referencial curricular nacional para evitar justamente os entraves legais: um parâmetro ou referencial não é obrigatório, nem fere a autonomia de Estados e Municípios. De todo modo, se o parâmetro ou referencial são de boa qualidade, acabam se impondo. Essa tendência no Brasil foi reforçada e acelerada pelo fato de o Ministério ser um grande comprador de livros didáticos e ter introduzido, a partir de 1996, a avaliação desses livros com base precisamente nos parâmetros. (Souza, 2005, p.123).

O livro didático torna-se, assim, elemento aglutinador do currículo nacional: a partir da universalização do atendimento aos alunos do Ensino Fundamental, por meio do PNLD, 100\% dos livros correspondentes às disciplinas do núcleo comum, que entram nas escolas públicas brasileiras para o alunado desse nível de ensino, são avaliados pedagógica e metodologicamente pela equipe governamental, que tem, entre outros critérios, os Parâmetros Curriculares Nacionais como norteadores.

Desse modo, os livros que alunos e professores - sujeitos centrais das escolas - têm em mãos na sala de aula estabelecem condições objetivas para a incorporação da reforma curricular, implementada no governo FHC às práticas escolares, de modo que tal reforma não ficasse circunscrita ao âmbito prescritivo.

Em suma, a implementação oficial da avaliação dos livros didáticos foi instituída em função da questionável qualidade dos livros comprados anteriormente (imputada à desqualificação do docente, incapaz para escolher o seu livro de uso), de assegurar a ausência de erros conceituais, de preconceitos e inconsistências metodológicas, porém, também cumpriu outro papel: a de legitimar uma reforma curricular.

\section{A Santillana no Brasil e as obras coletivas (Editora Moderna)}

Por motivos diversos (idioma, extensão territorial, medidas protecionistas de mercado que conviviam com relações bilaterais assimétricas com os EUA etc.), o Brasil teve a entrada maciça das empresas espanholas somente no final do século XX, quando estas já estavam fortemente estabelecidas em grande parte da América Latina, mas rapidamente passaram a dominar setores nacionais importantes.

Entender como se deu essa entrada no âmbito da educação implica tratar com mais proximidade dois temas: a entrada dos grandes grupos editoriais de livros didáticos espanhóis no Brasil - grupos que estão produzindo e comercializando produtos que entram efetivamente nas 
escolas de todo o país, (como já se viu, o governo brasileiro assegura a compra e distribuição gratuita desse dispositivo didático para a maior parte dos alunos da rede pública nacional) - e a análise da natureza sociopolítica e econômica da implementação de uma disciplina no currículo escolar (no caso da língua espanhola).

A análise desses fenômenos, inclusive de suas potenciais articulações (editoras, fomentoà língua espanhola, produçãoeentrada dedeterminados materiais nas escolas, formação de professores etc.), nos traz elementos para entender a complexidade do currículo desenvolvido nas escolas, que está além de seus muros, visto que nossa abordagem nos faz estabelecer o vínculo estreito entre Estado, economia, cultura e educação.

Não trataremos, aqui, da implementação do Espanhol como disciplina escolar no Brasil, mas faremos uma reflexão sintética de como a entrada do capital internacional nesse período fez parte de uma reconfiguração do mercado dos livros didáticos do Brasil.

Na década de1990, o mercadodos didáticosseconstituía, basicamente, de nove editoras que dominavam o segmento: Saraiva, FTD, Cia. Editora Nacional, Editora do Brasil, Ática, Scipione, Moderna, Atual e o IBEP.

Todas essas editoras tinham sua sedeem São Paulo e se caracterizavam, sobretudo, por serem compostas por empresas familiares nacionais (exceção feita à FTD, que é de origem francesa, e pertencente à ordem religiosa dos Irmãos Maristas) que se consolidaram na década de 1970, beneficiadas notadamente pelo aumento do alunado da rede pública, em face dos investimentos do Estado em educação no período ditatorial, buscando a ampliação do acesso.

Excetuando-se a Cia. Editora Nacional, as demais editoras têm seu grande salto quantitativo de vendas de livros didáticos devido às reformas na educação iniciadas com a Lei de Diretrizes e Bases da Educação Nacional - LDB 4024/61. Paixão (1998, p.156) relata que essa lei possibilitou a expansão da rede pública de ensino, e, consequentemente, incrementou o negócio dos didáticos.

Porém, como já se viu, a partir do final da década 1990 houve uma alteração significativa nesse quadro, com a formação e a entrada de grandes grupos no segmento dos didáticos. No início do século XX, apenas a Editora do Brasil era independente, sendo que as demais passaram a fazer parte de grandes grupos editoriais:

\footnotetext{
$\checkmark$ Grupo Saraiva, formado pelas editoras Saraiva, Atual e Formato;

$\checkmark$ Ática e Scipione, atualmente pertencentes ao Grupo Abril;

$\checkmark$ IBEP/Cia. Editora Nacional;

$\checkmark$ FTD, que adquiriu a Quinteto Editorial;
} 
$\checkmark$ Editora Moderna, que em 2001 foi adquirida pela espanhola Santillana de Edições, do Grupo Prisa. Também pertencem ao grupo a Editora Objetiva, a Editora Salamandra e a Richmond.

A partir dos anos 2000, a Editora Positivo, pertencente ao grupo paranaense Positivo, que tem sua marca assegurada justamente por meio da comercialização de "sistemas apostilados de ensino" e de computadores, também começou a despontar nas compras governamentais editando livros didáticos.

No caso da Santillana no Brasil, trata-se de entender a complexidade da entrada das empresas espanholas no país e como elas solidificam sua presença num curto período. Também a entrada do grupo nacional Positivo, chama a atenção, uma vez que foram novas forças entrando no campo de disputa dos didáticos, dando novas dinâmicas a esse mercado e inserindo novos materiais didáticos na rede pública de educação. Tais grupos reconfiguram o mercado nacional dos livros escolares, com um marketing mais agressivo em relação ao poder público (esferas governamentais e escolas) e em decorrência do poder de investimento que possuem.

A expansão das editoras espanholas para vários países da América Latina (e não só no Brasil) é um fenômeno que tem chamado a atenção, inclusive dos próprios espanhóis, que se posicionam de modo diverso.

Martinez Bonafé (2002, p.90-91), em obra sobre as políticas do texto escolar, diz que tanto a expansão do modelo curricular espanhol para vários países da América Latina quanto a transnacionalização das indústrias editoriais nos últimos anos podem significar uma nova forma de colonialismo cultural. O autor cita a progressiva implantação da Santillana na América Latina como um exemplo significativo desses potentes grupos que operam em diferentes países. Segundo Martinez Bonafé, "estes dois fatores - homogeneização curricular e expansão editorial - terão uma importante repercussão cultural em médio prazo".

As editoras de didáticos, ao lado dos investidores financeiros por trás de algumas universidades privadas, são protagonistas da inserção do setor de educação brasileiro na economia globalizada. De acordo com artigo de Aguiar (2003), publicado na revista Época, o negócio da educação no Brasil é bilionário, movimentando 13,5\% do Produto Interno Bruto (PIB) brasileiro. Sozinho, esse setor é maior do que os setores de óleo e gás somados, energia e telecomunicações. Como alvos dos investidores estão as universidades privadas, os cursos de línguas, escolas de treinamento profissional, as empresas de software educacional e as editoras de didáticos. 
De acordo com Isabel de Polanco (2001), filha de Jesús de Polanco e dirigente do Grupo Santillana, há uma especificidade requerida das empresas que atuam em países distintos com a venda de livros didáticos: a necessidade de adaptar a elaboração de materiais que tenham qualidade às características e requisitos locais, em que devem também ser levados em consideração aspectos comerciais e de preço. Polanco (2001) ressalta que essa bipolaridade também ocorre com os materiais destinados ao ensino de idiomas.

Seguindo a lógica da declaração de Polanco, ao adquirir a Moderna, a Santillana também adquiriu a cultura local da empresa, responsável em grande parte pelo sucesso da mesma no espaço nacional. Era estratégica a conservação de algumas práticas locais que dão a sustentação para a empresa no país. Entretanto, um olhar mais atento para a atuação da Moderna durante a gestão Santillana nos apresenta algumas marcas globais na produção dos livros didáticos, passíveis de serem vistas no pouco tempo da gestão espanhola. $\mathbf{O}$ depoimento abaixo apresenta elementos para a compreensão de como processos globais na produção de material didático vão sendo assimilados na educação do país:

No final de novembro de 2001, fui convidada pela editora Moderna para participar da produção de dois livros didáticos de Língua Portuguesa para a $3^{\text {a }}$ e $4^{\text {a }}$ série do Ensino Fundamental. Foi dito que os livros seriam produzidos a quatro mãos, processo chamado pela editora de obra coletiva com cessão exclusiva de direitos.

Houve uma conversa inicial para explicação de todo o processo. O modelo a ser seguido era um modelo espanhol de muita aceitação na Espanha e em países da América do Sul. O público alvo eram as escolas particulares que, no dizer dos professores, sabiam, em Língua Portuguesa, trabalhar com textos, mas tinham dificuldade com a gramática. Os livros entrariam no mercado para concorrer com os mais populares de outras editoras e, inicialmente, não seriam enviados ao MEC para avaliação.

Coube a mim e à colega com quem produzi os livros: produção, elaboração, seleção e adaptação de textos (alguns em espanhol), atividades, respostas, orientações didáticas, bibliográficas, indicação de sites ao professor, seleção e sugestão de imagens.

O envio de material ocorreu, em sua maior parte, via e-mail. Os pagamentos ocorreram dentro do prazo.

Nosso nome, acompanhado de um breve currículo, aparece na $1^{\underline{a}}$ contra capa dos quatro livros da coleção, junto com os demais autores, como Equipe de Elaboração. Internamente, não há citação de nosso nome como autoras de alguns textos. 
Concluímos o trabalho, que nos competia fazer, mais ou menos, dois meses depois de contratadas, em início de março de 2002. Quando a editora publicou o livro, houve um coquetel de lançamento para o qual não recebi convite. Também não recebi a coleção pronta, que só conheci no $2^{\circ}$ semestre de 2003 , depois de duas solicitações minhas, utilizando o campo do site da editora para contatos a respeito da Coleção.

Heloisa Ramos, autora de obra coletiva lançada pela Editora Moderna, Depoimento feito para Célia Cassiano. 12/11/2003)

O depoimento acima nos permite verificar um marco de ação global da Santillana na produção do material didático nele discriminado, na medida em que a estrutura e o projeto do livro já vêm predeterminados, à luz de produto desenvolvido na Espanha e em outros países da América Latina. Porém, em nosso entendimento, isso não apaga a instância dessa autoria, uma vez que a autora elaborou, de fato, todos os conteúdos da obra mencionada no depoimento.

Ressalte-se que a obra coletiva é uma modalidade de livro didático comum das editoras espanholas. Nesse tipo de obra, os autores passam a ter posição diferente no processo produtivo dos livros, que têm a estrutura predeterminada e pode (ou não) ser escrito por vários autores.

Ortiz (1994), ao analisar a mundialização da cultura, ressalta que o desenraizamento dos produtos é algo fundamental para o pensamento administrativo. Porter (apud Ortiz, 1994, p.151) afirma que "basicamente, o protótipo da estratégia global é aquela na qual a firma ganha vantagens pelo fato de possuir um alto volume de produção de uma linha comum de variedades de produtos".

Lembremo-nos de que a obrigatoriedade do espanhol no currículo oficial do Brasil representou um grande nicho de negócios que seabriu para as editoras de didáticos do país, e, em especial, paraa Santillana. Diferentemente das demais editoras que compartilham esse mercado, a produção de livros voltados para o ensino do espanhol é uma das especialidades dessa editora, além da produção dos didáticos de forma geral.

\section{A polêmica dos anos 2010: A entrada dos sistemas estruturados de ensino na rede pública}

No rol de potenciais temáticas que envolvem a intersecção entre políticas públicas, mercado editorial e implicações para o currículo desenvolvido nas escolas, optamos por apresentar outro tipo de produto que começa a entrar nessas instituições a partir da década de 2000 e implica alteração substancial para a rede pública de ensino: os "sistemas apostilados de ensino". 
Oriundos dos cursinhos pré-vestibulares, os "sistemas apostilados de ensino" passaram a ser vendidos diretamente às prefeituras brasileiras, na década de 2000, a partir de um "pacote" composto de material didático apostilado (sem autoria), formação de professores e todo o currículo organizado principalmente via web, de modo geral.

No caso desse produto, a questão é polêmica, mesmo com uma gama de opiniões contrárias à implantação desses sistemas apostilados de ensino na rede pública brasileira, uma vez que não passam por nenhum tipo de avaliação governamental, diferentemente do que ocorre com os livros didáticos comprados pelo governo federal, entre outras restrições de cunho pedagógico, a opção por tais sistemas não incide em ilegalidade, desde que a prefeitura que opte por tal produto informe ao governo, para que este não envie livros didáticos ao município por ocasião do PNLD, e que use verbas próprias do município para a compra do sistema apostilado.

Assim, ainda que o debate sobre as novas tecnologias em relação ao livro didático impresso tome corpo na mídia e na academia, na década de 2010 podemos observar em muitos municípios a substituição do livro didático pelos "sistemas apostilados de ensino", que são vendidos para todos os níveis de ensino, inclusive para a educação infantil.

Tal concepção pedagógica, de certo modo, é contrária a todas as possibilidades de interação e exploração potencializadas pelos novos meios ou por algum tema que interesse aos alunos, inclusive não potencializa que se contemple a diversidade (cultural, pedagógica) existente na escola (principalmente pública), uma vez que nessa metodologia de ensino o conteúdo abordado nas apostilas (impressas) deve ser dado, obrigatoriamente, nas datas previstas pelos docentes que, nesse processo, passam também a ter pouca autonomia em sala de aula. Inclusive, como parte do "pacote", também há todo um processo de formação da editora, via web, bem como amparo pedagógico ao aluno e ao docente (via web, também).

Na matéria publicada na revista IstoÉ, de 20/12/2006, no artigo intitulado "A didática da esperteza", Chico Silva destaca que "prefeitos encaixotam livros escolares cedidos pelo MEC em troca de um sistema de apostilas caro e de qualidade duvidosa”. Para fundamentar essa afirmação, o articulista considerou que 129 municípios do Estado de São Paulo (um quinto dos 645) deixam de usar os livros didáticos enviados pelo MEC (por ocasião do PNLD), optando por sistemas de ensino. Os dirigentes dessas localidades conseguiram bancar tal opção destinando boa parte dos recursos recebidos em decorrência do Fundo de Manutenção e Desenvolvimento do Ensino Fundamental (Fundef). Por ocorrências dessa ordem, a Resolução no 6o, de 20/11/2009 dispõe sobre a obrigatoriedade 
de as redes de ensino assinarem termo de adesão para participar do PNLD. Ou seja, a opção por esses sistemas estruturados de ensino não incide em ilegalidade, desde que a prefeitura que opte por tal produto informe ao governo, para que este não envie livros didáticos ao município por ocasião do PNLD, e que use verbas próprias do município (Fundeb) para a compra do sistema apostilado.

Isto posto, Silva (2006) acrescentou que o material didático dos sistemas de ensino não passam por nenhum tipo de avaliação governamental, diferentemente do que ocorre com os livros didáticos enviados pelo MEC, sequer são selecionados pelos docentes e profissionais da Secretaria da Educação dos Municípios, uma vez que são comprados nos órgãos centrais das prefeituras. Ainda assim, esse tipo de iniciativa municipal não é ilegal, pois os municípios têm autonomia na gestão e nos métodos de ensino. Nesse artigo, ainda, o articulista apresentou, entre outros, o caso de Taubaté, município localizado a $130 \mathrm{~km}$ de São Paulo que, provavelmente, está entre os que justificam o "endurecimento" do governo, com a já citada Resolução no 6o, de 2009.

No segundo semestre de 2005 o prefeito Roberto Peixoto (PSDB) encomendou 35 mil livros ao MEC. Meses depois, estranhamente mudou de ideia e entrou na onda das apostilas. Os livros gratuitos foram despachados para um galpão e os alunos obrigados a se deparar com graves erros como os vistos numa apostila da sexta série. No mapa-múndi, a Antártida foi parar onde é a Groelândia, o território gelado pertencente à Dinamarca. No mesmo desenho, o Estreito de Bening, o canal que separa o Alasca (EUA) da Sibéria (Rússia), foi grafado como Bening.

A má qualidade da apostila foi atestada por Liste Arevalo, diretora do departamento de Administração e Economia da Educação da USP: "O material é de segunda categoria. A estética é pobre e o conteúdo, inadequado para uma criança da sexta série". (...) "Duvido que o prefeito colocasse os filhos dele em uma escola com esse tipo de apostila”, completou Arelalo.

De acordo com o articulista, esse sistema apostilado foi produzido pela editora curitibana Expoente, que ganhou a concorrência em Taubaté.

A concorrência no segmento dos sistemas de ensino é bastante acirrada, porque conta tanto com empresas tradicionais do setor como Anglo, Objetivo, COC e Positivo, como com os grandes grupos do setor dos didáticos, que também passaram a produzir e comercializar sistemas de ensino. 
Esse processo justifica-se, certamente, em decorrência da expansão dos sistemas de ensino, que passaram a ocupar espaços antes destinados prioritariamente ao livro didático - primeiramente, em algumas escolas na rede particular de ensino e, posteriormente, na rede pública, por meio da negociação feita com as prefeituras municipais - somando-se ao potencial de ganhos advindos da venda desse tipo de produto, que impressionam!

A comercialização dos sistemas de ensino em Taubaté, mencionada por Mendes no artigo da revista Isto É (20/06/2006), custou aos cofres públicos R \$33,4 milhões por três anos. Nesse artigo a prefeitura da cidade justificou o investimento pela contraposição do serviço oferecido pela empresa: material didático complementar, treinamento do corpo docente, acesso a um portal de educação e um disque-dúvidas.

O dimensionamento dos gastos com os sistemas de ensino pode se dar à luz da contraposição do gasto de Taubaté, que é um pequeno município brasileiro ( $\mathrm{R} \$ 33$ milhões) contraposto ao investimento do governo federal desse período. Ou seja, em 2004, por meio do PNLD de 2005, o FNDE/ MEC investiu R\$ 619 milhões para atender os 31 milhões de alunos de $5^{\underline{a}}$ a $8^{\underline{a}}$ série (livros de todas as disciplinas) e da $1^{\underline{a}}$ série, além de fazer reposição para os alunos de $2^{\underline{a}}$ a $4^{\underline{a}}$ séries das 149.968 escolas do então Ensino Fundamental de oito anos da rede pública (FNDE, 2013). No caso do Ensino Médio, em 2005, para o PNLEM de 2006 (Programa Nacional do Livro Didático para o Ensino Médio) - nível de ensino que estava começando a receber livros didáticos por meio das compras governamentais, foram investidos, aproximadamente, 143 milhões, para atender 3.253 escolas públicas brasileiras, com Livros de Português e Matemática para os 7 milhões de alunos dos 3 anos do Ensino Médio, em todo o país.

Em síntese, o governo federal investiu (2004 e 2005) R\$ 762 milhões para enviar os livros supramencionados, de praticamente todas as disciplinas, aos 38 milhões de alunos matriculados nos ensinos Fundamental e Médio das escolas públicas dos 5.564 municípios do país (com poucas exceções, os livros enviados pelo PNLD têm previsão de uso de três anos). Em contraposição, o município de Taubaté, com 278 mil habitantes (IBGE, Censo Demográfico 2010) e, aproximadamente, $40 \mathrm{mil}$ estudantes matriculados, investiu 33milhões para a compra de um sistema de ensino (por três anos).

Assim, é por conta desse mercado promissor que se estabelece a retirada do livro didático da escola e a entrada dos grandes grupos do segmento dos didáticos nessa disputa. Ou seja, o objetivo é não perder mercado, e não defender um ou outro material didático ou metodologia de ensino. Além disso, as editoras também entram legalmente na formação 
de professores da rede pública, espaço que até então não era ocupado por essas empresas e que também se apresenta como mercado promissor.

Umbomexemplodaforçadenegóciosquerepresentaacomercialização dos Sistemas Estruturados de Ensino no Brasil é a entrada do gigantesco grupo britânico Pearson, que é considerado um dos maiores grupos de educação do mundo. A editora Pearson entrou no mercado educacional brasileiro, em 2010, no segmento dos materiais didáticos, ao adquirir os Sistemas de Ensino SEB, (COC, Pueri Domus, Dom Bosco e Nane); além de já ter significativa participação na Companhia das Letras.

De acordo com matéria jornalística de Beth Koike, publicada no jornal Valor Econômico em julho/2013, o Brasil é um dos quatro mercados prioritários, ao lado de China, Índia e África do Sul, para novos investimentos, sendo que a meta da empresa é chegar, em 2018, como um dos cinco maiores grupos educacionais do país por meio de crescimento orgânico de $20 \%$ ao ano e aquisições. Hoje, a Pearson já se posiciona entre as dez maiores no mercado brasileiro, sendo este o quarto mais importante mercado para o grupo britânico, que fechou o ano de 2012 com faturamento de US\$ 9,7 bilhões.

Nesta matéria, segundo Juan Romero, presidente da Pearson América Latina, que ocupa a presidência da unidade brasileira interinamente, além de investir no segmento dos sistemas apostilados, a companhia quer expandir negócios relacionados a prestação de serviços como, por exemplo, consultorias pedagógica, estratégica e financeira para escolas.

Hoje, a venda desse tipo de serviço já representa mais de 50\% do faturamento no Brasil e quase $40 \%$ no mundo. Vale destacar que esse percentual no país é superior devido aos sistemas de ensino

O diretor presidente da Pearson do Brasil, Guy Gerlach, em declaração para Oliveira (jornal Valor Econômico, de 10/04/2012) diz que "as apostas estão na ampliação de produtos e tecnologias para a escola pública. Por meio do Núcleo de Apoio à Municipalização do Ensino (Name), a Pearson já atende escolas em 124 municípios do país, atendendo mais de $200 \mathrm{mil}$ alunos. O plano é chegar agora na gestão dessas escolas." Considerou, ainda, que a empresa tropicalizou um produto já amplamente utilizado nos Estados Unidos para as necessidades do país, o PowerSchool, um software de gestão que atende mais de 50 milhões em todo o mundo.

Assim, inegavelmente, a meta das empresas que comercializam os sistemas de ensino é o grande mercado representado pela rede pública de ensino brasileira.

Apesar de todo aparato tecnológico no entorno desses produtos, além da obscuridade que atualmente a comercialização dos sistemas de ensino apresenta, uma vez que são vendidos diretamente para as prefeituras dos 
municípios brasileiros, sem passar por nenhuma instância de avaliação, nem pela seleção dos profissionais da educação local, inegavelmente o que se vende é a previsibilidade do trabalho com os conteúdos a partir de um currículo totalmente estruturado.

Na própria origem do material e na sua trajetória dos cursinhos prévestibulares para a rede particular de ensino e, desta, para a rede pública, pode-se constatar características do ensino pressuposto nesse produto.

Como já se mencionou, os "sistemas de ensino" são originários dos cursinhos pré-vestibulares, surgidos na década de 1950 quando a concorrência para o acesso às vagas nas universidades públicas aumentou. De acordo com matéria de Camila Pereira e Renata Betti sobre tais instituições, na revista Veja:

\footnotetext{
"Desde que surgiram, eles sempre se concentraram em ensinar macetes das provas e em treinar os alunos para se sair bem nesse tipo específico de concurso. Frases para fixar a tabela periódica, por exemplo, ajudaram gerações a passar no concurso. Como muitos dos vestibulares ainda demandam alta dose de decoreba, técnicas de memorização, à base de músicas e rimas, são até hoje comuns.

Embora muito da essência dos antigos cursinhos permaneça, do ponto de vista dos negócios eles se profissionalizaram. Foi ainda na década de 70 que alguns empresários do setor vislumbraram a chance de se expandir para o ensino básico, depois para o ramo de venda de apostilas e serviços e, finalmente, na década de 9o, para o prolífero mercado de ensino superior. Os cursinhos, no entanto, nunca ficaram de lado. Com classes lotadas de alunos e uma infraestrutura simples, oferecem margens de lucro de $20 \%$, em média, segundo um estudo da consultoria Hoper. É o dobro das margens obtidas com escolas de ensino médio. (Pereira e Betti, 2009)
}

Como se viu, boa parte destes cursinhos pré-vestibulares expandiu sua força de negócios, na década de 1970, por meio do atendimento ao ensino básico, por meio escolas próprias (Positivo, Objetivo, Etapa etc) e da venda dos sistemas de ensino para a rede privada.

A novidade, a partir dos anos 2000, é a venda desses sistemas de ensino diretamente para as prefeituras da rede pública que, em muitos casos, tem a qualidade duvidosa.

Porém, é inegável o apelo que esses materiais têm! Em 2010, foram computadas 165 municípios (dos 645 do Estado de São Paulo), que abriram mão de receber gratuitamente os livros didáticos por meio do PNLD para gastarem milhões de seus recursos próprios comprando sistemas de ensino de empresas como Positivo, COC, Objetivo, Expoente, 
entre outros oriundos das grandes editoras de didáticos (Ática, Moderna, Saraiva, Scipione, entre outras). Nesse processo, os interesses comerciais das editoras são muitos e, diga-se de passagem, os ganhos advindos dessa venda são muito maiores do que os gerados pela venda dos livros didáticos, como já foi demonstrado, anteriormente.

De fato, o mercado escolar brasileiro é muito atrativo, não só pelos números que apresenta, mas também pelas suas possibilidades de crescimento, diferentemente dos países europeus, por exemplo, em que as taxas de natalidade, via-de-regra, caem ano a ano. Além disso, o gigantismo das compras governamentais inegavelmente apresenta grande apelo aos interesses comerciais implicados na venda de materiais didáticos e na prestação de serviços para o setor público que, por vezes, extrapolam o interesse meramente pedagógico que deveria balizar a questão do ensino público.

\section{O caso de Valinhos}

Na contraposição dessa tendência de municípios substituírem os livros didáticos por sistemas de ensino, em 2013 pode-se constatar, no site da Prefeitura Municipal de Valinhos, pertencente ao estado de São Paulo, que os professores tiveram a oportunidade de votar, em 2012, e optaram pelo fim da adoção de sistema de ensino adotado há alguns anos nesse município e solicitaram o retorno dos livros didáticos fornecidos por meio do PNLD. Tal consulta aos docentes fez parte da proposta de implantação de uma gestão participativa na área da Educação do município, conforme plano de governo do prefeito Clayton Machado (PSDB).

De acordo com o Secretário da Educação, Danilo Sorroce, nada melhor do que os próprios professores, que utilizam as apostilas no dia-adia das salas de aula, para avaliarem se o sistema correspondeu ou não às necessidades do ensino municipal. "A votação foi baseada em parâmetros técnicos que foram definidos pelos próprios professores”.

Assim, frente à posição dos professores da rede de Valinhos, o contrato com a Editora Moderna não será renovado e "isso representará uma economia aos cofres municipais, já que o Ministério da Educação fornece gratuitamente livros didáticos de ótima qualidade aos municípios", declarou Sorroce.

O sistema foi introduzido na rede municipal em $2007 \mathrm{e} \mathrm{em} \mathrm{seis} \mathrm{anos}$ foram gastos com a compra das apostilas mais de R\$ 9 milhões. De 2007 a 2010, o contrato era com Múltipla Editora, porém em 2011 e 2012, o contrato passou para Editora Moderna, da espanhola Santillana, que comercializa o Sistema Uno de Ensino. 
Na contramão da gratuidade, para o município, dos livros didáticos recebidos pelo governo federal, o material apostilado é integralmente financiado pelo município que o adota e normalmente com um valor significativo, como já foi exemplificado anteriormente no caso de Taubaté e como pode ser observado por meio dos valores gastos com apostilas pela Prefeitura de Valinhos, desde o ano de 2007:

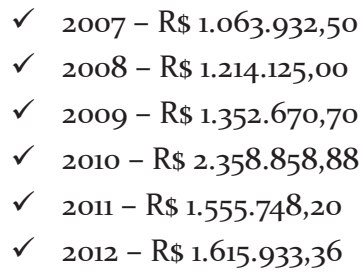

Total: R\$ 9.161.268,64

O secretário de Valinhos explicou que os recursos que deixarão de ser gastos com as apostilas serão aplicados em projetos que garantam maior qualidade à educação do município, como cursos de capacitação para os profissionais da área e a inserção da rede municipal no contexto tecnológico.

É interessante constatar os depoimentos do professor de História Gersio Pelegatti, da EMEB Prefeito Jerônymo Alves Corrêa de Valinhos, que está há nove anos na rede municipal de ensino e votou pelo fim do uso do sistema apostilado «para a possibilidade de liberdade e autonomia do professor em relação a escolha do livro didático», segundo ele, que já trabalhou tanto com os livros didáticos do PNLD e com os sistemas de ensino,

\footnotetext{
"os livros didáticos do Ministério da Educação passam por uma avaliação técnica efetuada por especialistas. São vários títulos disponibilizados, o que dá aos professores a possibilidade de escolha dentro de seus próprios critérios. Já a adoção das apostilas não foi de forma democrática. O sistema foi implantado a partir de uma ação de um governo, sem consultar aos professores". (site da Prefeitura de Valinhos, julho/2013).
}

Assim, como já foi apresentado, a polêmica na compra dos sistemas de ensino envolve muitos aspectos, entre eles a própria interferência na autonomia dos professores, que não são consultados sobre o material que deverão utilizar em sala de aula e passam a ficar presos a um rígido roteiro, transformando-se em meros aplicadores do material didático. 
Além disso, como já se disse, é um material que não passa por nenhum tipo de avaliação oficial, como ocorre com os livros didáticos adquiridos pelo PNLD e o município têm de adquirir os sistemas de ensino com verbas próprias, que são expressivas, ao passo que os livros didáticos são recebidos gratuitamente, uma vez que são pagos com verba federal e têm custos de aquisição e distribuição relativamente baixos, devido à capacidade de negociação que o governo federal tem devido ao gigantismo da compra decorrente do PNLD.

De fato, a questão é polêmica!

\section{CONCLUSÃO}

A constatação de que o oligopólio no mercado brasileiro dos livros didáticos passou das empresas familiares para o dos grandes grupos, nacionais e internacionais nos impõe a necessidade de problematizar esse processo, já que novas questões são postas, dado que alguns desses grupos são verdadeiros impérios midiáticos e grupos empresariais com atuação em vários setores. Além da expressiva capacidade de investimento desses grandes grupos que compõem o oligopólio dos didáticos, salta aos olhos, também, de fato, a entrada maciça de tais grupos na formação de professores e, por vezes, ficarem responsáveis pelo desenvolvimento de todo o currículo público de alguns municípios, no caso da comercialização dos "sistemas apostilados de ensino".

Tal panorama apresenta elementos que tencionam a questão dos limites entre o público e o privado e apontam para novas relações que doravante instauradas entre grandes grupos que dominam o setor dos didáticos, o Estado e a escola. Entendemos que compreender os saberes selecionados na sala de aula das escolas públicas brasileiras passa, também, pelo conhecimento desses processos.

\section{REFERÊNCIAS BIBLIOGRÁFICAS}

AGUIAR, Marcelo. "De olho nas escolas". Seção de Economia e Negócios. Revista Época. São Paulo: 08/09/2003.

BATISTA. Antonio Augusto Gomes. "O PNLD e a avaliação do livro didático brasileiro para a escola fundamental”. Presença Pedagógica, no 15, vol. 3. Belo Horizonte: Dimensão, maio-julho, 1997. pp.84-88. 
BATISTA. "Um objeto variável e instável: textos, impressos e livros didáticos”. In: ABREU, Márcia. Leitura, História e História da leitura. Campinas; São Paulo: Mercado das Letras, Associação de Leitura do Brasil; FAPESP, 2002.

BATISTA, ROJO, Roxane (Org.). Livro didático de língua portuguesa, letramento e cultura escrita. São Paulo: Mercado de Letras, 2003. pp. 25-68.

BEZERRA, Holien Gonçalves, LUCA, Tânia Regina de. "Em busca da qualidade -- PNLD História - 1996-2004”. In: SPOSITO, Maria Encarnação Beltrão(Org.). Livros didáticos de Geografia e História: avaliação e pesquisa. São Paulo: Cultura Acadêmica, 2006.

BIZZO, Nélio. "Falhas no ensino de Ciências". Revista Ciência Hoje. Vol.27, n 159. Abril, 2000.

CASSIANO, Célia Cristina de F. O mercado do livro didático no Brasil: do Programa Nacional do Livro Didático - PNLD à entrada do capital internacional espanhol (1985-2007). Tese de Doutorado. São Paulo: PUC, 2007.

FNDE, 2013 - Evolução do PNLD Ensino Fundamental - 2004 a 2013.

INEP. Censo da educação básica: 2012 - resumo técnico. Brasília: Instituto Nacional de Estudos e Pesquisas Educacionais Anísio Teixeira (INEP), 2013. Disponível em <http://www.fnde.gov.br/programas/livro-didatico/livro-didatico-dadosestatisticos> Acesso em: 30 . jun2013

KOIKE, Beth. "Pearson vai acelerar negócios em educação”. Jornal Valor Econômico. São Paulo: 19/07/2013.

MARTÍNEZ BONAFÉ, Jaume. Políticas del libro de texto escolar. Ediciones Morata: Madrid, 2002.

MEC. Plano Decenal de Educação para todos. Brasília: MEC, 1993. (versão acrescida).

OLIVEIRA, R. de. "Após investimentos de R\$ 1 bilhão, conselho de administração vem ao país em busca de resultados". Jornal Valor Econômico. São Paulo: 10abr2o12.

ORTIZ, Renato. 1994. Mundialização e Cultura. São Paulo: Brasiliense, 1994.

PAIXÃO, Fernando (Org. e Coord. do projeto). Momentos do Livro no Brasil. São Paulo: Ática, 1998.

PELUSO, Marília Luíza. “O processo de avaliação do livro didático de Geografia, uma aposta no futuro”. In: SPOSITO, Maria Encarnação Beltrão. Livros didáticos de Geografia e História: avaliação e pesquisa. São Paulo: Cultura Acadêmica, 2006.

PREFEITURA DE VALINHOS (site). "8o\% dos professores votam pelo fim do sistema apostilado na rede municipal”. Disponível em: <http://www.valinhos.sp.gov.br/ portal/index.php?option=com_content\&view=article\&id=2888:80-dosprofessores-votam-pelo-fim-do-sistema-apostilado-na-rede-municipal\&catid=34:n oticias\&Itemid=93> Acesso: $30 j u n 2013$ 
396 - Remate de Males 34.2

POLANCO. Isabel de. "Global y local en la estrategia del Grupo Santillana". II Congreso Internacional de la lengua española. Madrid: Centro virtual Cervantes. 2001. Disponível em: <http://cvc.cervantes.es/obref/congresos/valladolid/ponencias/ activo_del_espanol/2_la_edicion_en_espanol /polanco_i.htm> Acesso em: zodezzoo7.

SILVA, C. "A didática da esperteza". Revista IstoÉ. São Paulo: zodezzoo6.

SPOSITO, M.E.B (Org.). Livros Didáticos de História e Geografia: avaliação e pesquisa. São Paulo: Cultura Acadêmica, 2006. 